\title{
Imputed State-Level Prevalence of Achieving Goals To Prevent Complications of Diabetes in Adults with Self-Reported Diabetes — United States, 2017-2018
}

\author{
Yu Chen, $\mathrm{PhD}^{1}$; Deborah Rolka, $\mathrm{MS}^{1}$; Hui Xie, $\mathrm{PhD}^{1}$; Sharon Saydah, $\mathrm{PhD}^{1}$
}

Diabetes increases the risk for developing cardiovascular, neurologic, kidney, eye, and other complications. Diabetes and related complications also pose a huge economic cost to society: in 2017, the estimated total economic cost of diagnosed diabetes was $\$ 327$ billion in the United States (1). Diabetes complications can be prevented or delayed through the management of blood glucose (measured by hemoglobin A1C), blood pressure (BP), and non-high-density lipoprotein cholesterol (non-HDL-C) levels, and by avoiding smoking; these are collectively known as the ABCS goals (hemoglobin A1C, Blood pressure, Cholesterol, Smoking) (2-5). Assessments of achieving ABCS goals among adults with diabetes are available at the national level $(4,6)$; however, studies that assess statelevel prevalence of meeting ABCS goals have been lacking. This report provides imputed state-level proportions of adults with self-reported diabetes meeting ABCS goals in each of the 50 U.S. states and the District of Columbia (DC). State-level estimates were created by raking and multiple imputation methods $(7,8)$ using data from the 2009-2018 National Health and Nutrition Examination Survey (NHANES), 2017-2018 American Community Survey (ACS), and 2017-2018 Behavioral Risk Factor Surveillance System (BRFSS). Among U.S. adults with diabetes, an estimated $26.4 \%$ met combined ABCS goals, and $75.4 \%, 70.4 \%, 55.8 \%$, and $86.0 \%$ met $\mathrm{A} 1 \mathrm{C}<8 \%$, BP $<140 / 90 \mathrm{mmHg}$, non-HDL-C $<130 \mathrm{mg} / \mathrm{dL}$ and nonsmoking goals, respectively. Public health departments could use these data in their planning efforts to achieve ABCS goal levels and reduce diabetes-related complications at the state level.

\footnotetext{
*The American Diabetes Association recommends an A1C goal for many nonpregnant adults of $<7 \%$, and a less stringent $\mathrm{AlC}$ goal of $<8 \%$ is recommended for persons with other medical conditions and limited life expectancy. https:// care.diabetesjournals.org/content/diacare/suppl/2018/12/17/42.Supplement_1. DC1/DC_42_S1_2019_UPDATED.pdf.
}

This analysis included adults aged $\geq 20$ years who reported having received a diagnosis of diabetes (excluding gestational diabetes) from a health care provider. This report defined ABCS goals as $\mathrm{A} 1 \mathrm{C}<8 \%,{ }^{*} \mathrm{BP}<140 / 90 \mathrm{mmHg}$, non-HDL-C $<130 \mathrm{mg} / \mathrm{dL}$, and being a nonsmoker (4). Nonsmokers were

\section{INSIDE}

1671 COVID-19 Outbreak in an Amish Community Ohio, May 2020

1675 Mental Health-Related Emergency Department Visits Among Children Aged $<18$ Years During the COVID-19 Pandemic — United States, January 1October 17, 2020

1681 Risk Assessment and Management of COVID-19 Among Travelers Arriving at Designated U.S. Airports, January 17-September 13, 2020

1686 Multiple COVID-19 Outbreaks Linked to a Wedding Reception in Rural Maine - August 7September 14, 2020

1691 Declines in SARS-CoV-2 Transmission, Hospitalizations, and Mortality After Implementation of Mitigation MeasuresDelaware, March-June 2020

1695 Characteristics of Hospitalized COVID-19 Patients Discharged and Experiencing Same-Hospital Readmission — United States, March-August 2020

1700 Progress Toward Regional Measles Elimination Worldwide, 2000-2019

1706 Routine Vaccination Coverage - Worldwide, 2019

1712 QuickStats

Continuing Education examination available at https://www.cdc.gov/mmwr/mmwr_continuingEducation.html

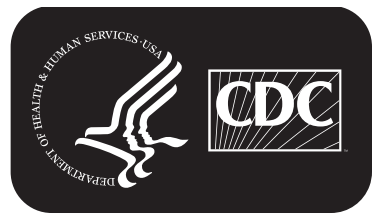

U.S. Department of Health and Human Services Centers for Disease Control and Prevention 
defined as those who provided negative responses to questions about smoking ( $\geq 100$ cigarettes in their lifetime and being a current smoker at the time of the survey). To estimate statelevel prevalence, the raking method ${ }^{\dagger}$ was first used to adjust BRFSS weights to the ACS on age, sex, race, health insurance status, education, and income to reflect the state population characteristics (7). Multiple imputation methods were used (8) to predict the values of $\mathrm{A} 1 \mathrm{C}, \mathrm{BP}$, and non-HDL-C for adults with self-reported diabetes in the weight-adjusted BRFSS data. $\$$ Variables common to both NHANES and BRFSS were used as predictors (i.e., age, sex, race, health insurance status, education, income, body mass index category, and health status). Prevalence was estimated by averaging the estimates from all imputed data sets, ${ }^{* *}$ and standard errors were pooled by combining the within-imputation variance and the between-imputation variance (8). For the nonsmoking goal, the state-level prevalence was estimated directly from

\footnotetext{
${ }^{\dagger}$ Raking method was used repeatedly by year and by the state to adjust 2017-2018 BRFSS weights to the 2017-2018 ACS. https://journals.sagepub. com/doi/pdf/10.1177/1536867X1401400104.

$\$ 2009$-2018 NHANES was used for conducting multiple imputations.

9 The study imputed the values of A1C in BRFSS based on the A1C information in NHANES and the shared predictors in NHANES and BRFSS. Similarly, values of $\mathrm{BP}$ and non-HDL-C were imputed based on the shared predictors in both data sets and the BP and non-HDL-C information respectively in NHANES.

** The multiple imputation method generated multiple data sets. Each imputed data set was then analyzed individually, and the final result was obtained by combining the results obtained from all the imputed data sets.
}

weight-adjusted BRFSS data. The national prevalence of each of the ABCS goals was a direct estimate from 2015-2018 NHANES. For prevalence of achieving ABCS goals, 90\% confidence intervals (CIs) were calculated to help illuminate meaningful differences while reflecting the uncertainty inherent in these modeled estimates. Analyses were conducted using SAS software (version 9.4; SAS Institute). This activity was reviewed by CDC and was conducted consistent with applicable federal law and CDC policy. ${ }^{\dagger \dagger}$

Among adults with self-reported diabetes, $26.4 \%$ met combined ABCS goals nationally, and state-level estimates ranged from $22.3 \%$ to $28.2 \%$ (Table). The lowest prevalence was in Wisconsin, and the highest was in Utah. Most of the states varied within the $90 \% \mathrm{CI}$ of the national prevalence.

For each ABCS goal, nationally, $75.4 \%$ met the A1C goal ( $<8 \%), 70.4 \%$ met the BP goal $(<140 / 90 \mathrm{mmHg}), 55.8 \%$ met the non-HDL-C goal $(<130 \mathrm{mg} / \mathrm{dL})$, and $86.0 \%$ met the nonsmoking goal. Among adults with diabetes who attained the $\mathrm{A} 1 \mathrm{C}$ goal, the lowest prevalence was $73.7 \%$ (Texas), and the highest prevalence $(77.2 \%)$ was in Alaska; all were within the $90 \% \mathrm{CI}$ of the national estimate. The lowest prevalence of meeting the $\mathrm{BP}$ goal was $62.8 \%$ in $\mathrm{DC}$, and the highest $(74.8 \%)$ was in Alaska. The lowest prevalence of achieving the non-HDL-C goal was $52.8 \%$ in Wisconsin, and the

\footnotetext{
†† 45 C.F.R. part 46, 21 C.F.R. part 56; 42 U.S.C. Sect. 241 (d); 5 U.S.C. Sect.
} 552a; 44 U.S.C. Sect. 3501 et seq.

The MMWR series of publications is published by the Center for Surveillance, Epidemiology, and Laboratory Services, Centers for Disease Control and Prevention (CDC), U.S. Department of Health and Human Services, Atlanta, GA 30329-4027.

Suggested citation: [Author names; first three, then et al., if more than six.] [Report title]. MMWR Morb Mortal Wkly Rep 2020;69:[inclusive page numbers].

\author{
Centers for Disease Control and Prevention \\ Robert R. Redfield, MD, Director \\ Anne Schuchat, MD, Principal Deputy Director \\ Ileana Arias, PhD, Acting Deputy Director for Public Health Science and Surveillance \\ Rebecca Bunnell, PhD, MEd, Director, Office of Science \\ Jennifer Layden, MD, PhD, Deputy Director, Office of Science \\ Michael F. Iademarco, MD, MPH, Director, Center for Surveillance, Epidemiology, and Laboratory Services
}

MMWR Editorial and Production Staff (Weekly)

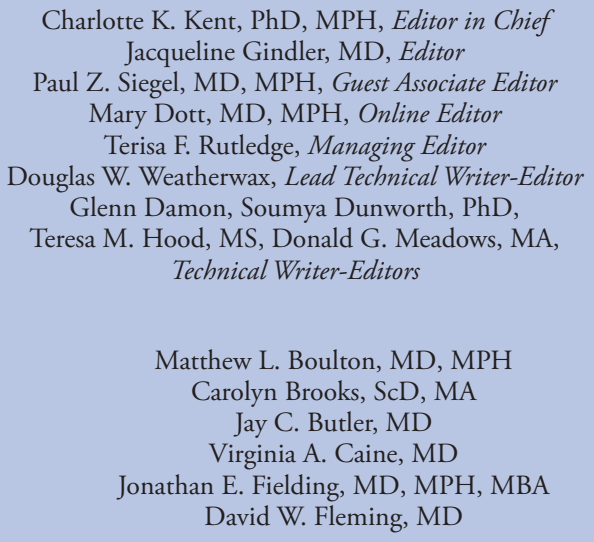

Charlotte K. Kent, PhD, MPH, Editor in Chief Jacqueline Gindler, MD, Editor

Paul Z. Siegel, MD, MPH, Guest Associate Editor Mary Dott, MD, MPH, Online Editor Terisa F. Rutledge, Managing Editor

Douglas W. Weatherwax, Lead Technical Writer-Editor Glenn Damon, Soumya Dunworth, PhD,

Teresa M. Hood, MS, Donald G. Meadows, MA, Technical Writer-Editors

Matthew L. Boulton, MD, MPH

Carolyn Brooks, ScD, MA Jay C. Butler, MD Virginia A. Caine, MD

Jonathan E. Fielding, MD, MPH, MBA David W. Fleming, MD

Martha F. Boyd, Lead Visual Information Specialist Alexander J. Gottardy, Maureen A. Leahy,

Julia C. Martinroe, Stephen R. Spriggs, Tong Yang, Visual Information Specialists

Quang M. Doan, MBA, Phyllis H. King, Terraye M. Starr, Moua Yang, Information Technology Specialists

MMWR Editorial Board

Timothy F. Jones, MD, Chairman Kate Galatas, MPH

William E. Halperin, MD, DrPH, MPH

Jewel Mullen, MD, MPH, MPA

Jeff Niederdeppe, $\mathrm{PhD}$

Celeste Philip, MD, MPH

Patricia Quinlisk, MD, MPH

\begin{abstract}
Ian Branam, MA, Acting Lead Health Communication Specialist Shelton Bartley, MPH, Lowery Johnson, Jacqueline N. Sanchez, MS, Health Communication Specialists Will Yang, MA Visual Information Specialist
\end{abstract}

Patrick L. Remington, MD, MPH Carlos Roig, MS, MA William Schaffner, MD Nathaniel Smith, MD, MPH Morgan Bobb Swanson, BS 
TABLE. Estimated prevalence* of achieving hemoglobin A1C, blood pressure, cholesterol, and avoiding smoking (ABCS) goals among adults with self-reported diabetes — United States, 2017-2018

\begin{tabular}{|c|c|c|c|c|c|}
\hline \multirow[b]{2}{*}{ Area } & \multicolumn{5}{|c|}{ Prevalence, \% (90\% Cl) } \\
\hline & ABCS goals ${ }^{\dagger}$ & $\mathrm{A} 1 \mathrm{C}<8 \%$ & $\mathrm{BP}<140 / 90 \mathrm{mmHg}$ & Non-HDL-C $<130 \mathrm{mg} / \mathrm{dL}$ & Nonsmoking \\
\hline Nationwide ${ }^{\S}$ & $26.4(22.5-30.3)$ & $75.4(72.7-78.1)$ & $70.4(67.4-73.4)$ & $55.8(51.7-59.9)$ & $86.0(83.6-88.4)$ \\
\hline Alabama & $24.5(21.2-27.7)$ & $75.4(72.7-78.1)$ & $69.0(65.9-72.0)$ & $57.9(53.7-62.1)$ & $85.5(83.8-87.2)$ \\
\hline Alaska & $25.4(18.5-32.4)$ & $77.2(71.2-83.2)$ & $74.8(68.3-81.3)$ & $54.4(47.6-61.1)$ & $87.4(84.4-90.5)$ \\
\hline Arizona & $24.2(21.3-27.2)$ & $74.8(71.3-78.4)$ & $70.9(67.7-74.1)$ & $54.7(51.0-58.4)$ & $87.6(85.9-89.4)$ \\
\hline Arkansas & $24.1(20.8-27.5)$ & $75.1(71.5-78.8)$ & $70.5(67.0-74.0)$ & $56.4(51.2-61.6)$ & $84.1(81.9-86.3)$ \\
\hline California & $25.0(21.8-28.2)$ & $74.6(71.5-77.8)$ & $71.4(68.0-74.8)$ & $54.6(50.2-59.0)$ & $91.0(89.1-92.8)$ \\
\hline Colorado & $26.1(22.5-29.7)$ & $76.8(73.7-79.9)$ & $72.4(68.7-76.1)$ & $56.4(52.9-59.9)$ & $87.9(86.1-89.6)$ \\
\hline Connecticut & $24.8(21.4-28.1)$ & $75.9(72.8-78.9)$ & $69.6(66.1-73.1)$ & $56.3(51.7-60.9)$ & $87.2(85.4-89.0)$ \\
\hline Delaware & $24.1(20.2-28.1)$ & $75.6(71.6-79.6)$ & $68.4(64.6-72.2)$ & $56.8(51.6-61.9)$ & $88.9(86.9-90.8)$ \\
\hline District of Columbia & $23.3(19.6-27.1)$ & $75.1(70.4-79.8)$ & $62.8(58.4-67.1)$ & $62.8(58.0-67.6)$ & $84.4(81.8-87.0)$ \\
\hline Florida & $25.0(21.4-28.6)$ & $75.8(72.0-79.5)$ & $68.2(64.7-71.7)$ & $55.6(51.9-59.3)$ & $89.2(87.3-91.1)$ \\
\hline Georgia & $24.5(21.3-27.7)$ & $74.6(71.0-78.2)$ & $69.3(66.2-72.3)$ & $57.5(54.0-61.0)$ & $87.0(85.1-89.0)$ \\
\hline Hawaii & $24.8(21.2-28.5)$ & $75.1(71.7-78.4)$ & $69.5(65.3-73.7)$ & $54.1(48.8-59.5)$ & $88.4(86.3-90.5)$ \\
\hline Idaho & $25.5(21.1-29.9)$ & $76.3(72.2-80.3)$ & $72.1(67.7-76.6)$ & $55.4(49.5-61.2)$ & $87.7(85.5-90.0)$ \\
\hline Illinois & $25.0(20.9-29.1)$ & $75.3(71.7-78.8)$ & $70.1(66.7-73.5)$ & $56.1(52.0-60.2)$ & $87.9(85.9-90.0)$ \\
\hline Indiana & $23.8(21.6-26.0)$ & $76.3(73.7-78.9)$ & $70.3(68.0-72.6)$ & $55.9(52.4-59.5)$ & $83.6(82.0-85.2)$ \\
\hline lowa & $23.7(21.0-26.5)$ & $75.8(72.1-79.5)$ & $69.6(66.6-72.5)$ & $53.9(50.9-56.8)$ & $87.2(85.7-88.7)$ \\
\hline Kansas & $24.3(22.0-26.6)$ & 75.6 (73.4-77.7) & $71.1(68.8-73.4)$ & $55.6(52.1-59.0)$ & $86.2(84.8-87.5)$ \\
\hline Kentucky & $24.3(21.3-27.2)$ & $75.3(72.1-78.5)$ & $71.2(68.2-74.3)$ & $57.3(54.2-60.4)$ & $80.9(78.8-83.1)$ \\
\hline Louisiana & $24.5(20.2-28.8)$ & $75.4(72.0-78.8)$ & $69.0(65.4-72.7)$ & $59.2(53.7-64.6)$ & $85.1(82.6-87.5)$ \\
\hline Maine & $25.3(21.7-29.0)$ & $75.8(73.1-78.5)$ & $71.3(68.7-73.9)$ & $56.1(51.3-60.8)$ & $85.8(83.9-87.7)$ \\
\hline Maryland & $26.5(23.8-29.3)$ & $76.4(73.2-79.7)$ & $70.1(67.3-72.9)$ & $58.2(55.1-61.3)$ & $88.5(86.8-90.2)$ \\
\hline Massachusetts & $26.2(21.9-30.4)$ & $76.3(72.3-80.2)$ & $71.3(67.3-75.3)$ & $56.3(50.3-62.2)$ & $87.5(85.0-90.0)$ \\
\hline Michigan & $24.6(22.2-27.1)$ & $76.1(72.5-79.8)$ & $69.6(66.6-72.6)$ & $56.2(53.2-59.3)$ & $86.3(84.8-87.8)$ \\
\hline Minnesota & $25.6(23.2-28.1)$ & 76.3 (73.9-78.6) & $71.2(68.8-73.7)$ & $56.1(52.8-59.5)$ & $87.6(86.3-89.0)$ \\
\hline Mississippi & $23.5(20.6-26.4)$ & $74.5(71.6-77.3)$ & $66.8(63.3-70.2)$ & $58.7(55.3-62.1)$ & $84.3(82.4-86.1)$ \\
\hline Missouri & $24.7(20.1-29.3)$ & $75.8(72.8-78.8)$ & $71.6(68.1-75.2)$ & $56.7(52.4-61.0)$ & $83.0(80.8-85.2)$ \\
\hline Montana & $25.2(20.9-29.5)$ & 76.0 (72.2-79.8) & $70.6(65.9-75.4)$ & $54.3(49.6-59.0)$ & $87.5(85.4-89.7)$ \\
\hline Nebraska & $25.5(22.4-28.6)$ & $76.1(73.7-78.6)$ & $71.0(67.9-74.2)$ & $55.1(51.5-58.7)$ & $89.3(88.0-90.6)$ \\
\hline Nevada & $23.2(17.6-28.8)$ & $75.1(69.7-80.5)$ & $69.2(64.4-74.0)$ & $55.9(48.9-62.9)$ & $85.9(82.5-89.4)$ \\
\hline New Hampshire & $26.9(22.4-31.4)$ & $76.2(71.1-81.3)$ & $72.0(68.0-75.9)$ & $55.9(51.3-60.6)$ & $89.2(87.3-91.1)$ \\
\hline New Jersey & $26.2(21.1-31.3)$ & $76.2(71.7-80.7)$ & $70.1(65.4-74.8)$ & $55.3(50.8-59.9)$ & 88.4 (85.9-91.0) \\
\hline New Mexico & $24.6(21.1-28.1)$ & $73.9(69.9-77.8)$ & $71.3(67.5-75.2)$ & $54.8(49.7-59.9)$ & $86.4(84.5-88.4)$ \\
\hline New York & $23.5(20.5-26.5)$ & $74.6(71.1-78.0)$ & $69.6(66.5-72.8)$ & $55.8(52.0-59.7)$ & $88.4(87.0-89.8)$ \\
\hline North Carolina & $24.6(20.4-28.7)$ & $76.0(72.2-79.8)$ & $69.2(65.4-73.1)$ & $57.5(53.0-62.1)$ & $84.1(81.1-87.1)$ \\
\hline North Dakota & $23.7(21.1-26.3)$ & $75.9(72.1-79.7)$ & $71.6(68.4-74.8)$ & $55.1(51.2-58.9)$ & $82.4(79.7-85.0)$ \\
\hline Ohio & $24.6(22.1-27.1)$ & $76.0(73.8-78.1)$ & $69.9(67.4-72.4)$ & $55.8(52.7-59.0)$ & $84.7(83.1-86.3)$ \\
\hline Oklahoma & $24.8(21.8-27.8)$ & 75.7 (72.9-78.5) & $72.0(68.7-75.4)$ & $54.6(50.7-58.5)$ & $85.4(83.6-87.3)$ \\
\hline Oregon & $24.8(21.3-28.3)$ & $76.1(71.8-80.4)$ & $72.6(68.1-77.1)$ & $54.9(50.7-59.2)$ & $84.2(81.3-87.0)$ \\
\hline Pennsylvania & $25.3(21.7-28.9)$ & $76.0(72.2-79.7)$ & $70.3(66.5-74.1)$ & $56.6(51.4-61.9)$ & $85.4(83.3-87.5)$ \\
\hline Rhode Island & $25.2(21.1-29.2)$ & $75.9(72.1-79.7)$ & $70.5(66.8-74.1)$ & $55.3(50.4-60.3)$ & $87.7(85.5-89.8)$ \\
\hline South Carolina & $24.6(22.3-26.9)$ & $74.9(72.3-77.4)$ & $67.9(65.7-70.1)$ & $58.4(55.9-60.9)$ & $85.2(83.5-86.9)$ \\
\hline South Dakota & $24.5(20.1-28.8)$ & $76.2(71.4-81.0)$ & $70.0(65.2-74.8)$ & $55.3(49.0-61.6)$ & $84.0(80.3-87.7)$ \\
\hline Tennessee & $22.5(18.6-26.4)$ & $74.9(71.5-78.4)$ & $69.8(66.1-73.5)$ & $56.7(52.8-60.5)$ & $79.3(76.7-81.9)$ \\
\hline Texas & $23.5(19.4-27.6)$ & $73.7(69.3-78.0)$ & $70.1(63.9-76.3)$ & $54.9(49.8-60.0)$ & $88.4(85.6-91.1)$ \\
\hline Utah & $28.2(25.1-31.3)$ & $76.0(72.3-79.6)$ & $73.6(70.1-77.1)$ & $54.7(50.6-58.8)$ & $91.8(90.3-93.4)$ \\
\hline Vermont & $25.4(21.8-29.1)$ & $75.6(71.8-79.3)$ & $71.2(67.3-75.2)$ & $57.1(52.7-61.6)$ & $86.0(83.4-88.7)$ \\
\hline Virginia & $25.5(22.2-28.8)$ & $75.7(72.1-79.3)$ & $69.3(65.9-72.7)$ & $56.6(53.3-60.0)$ & $87.3(85.7-88.8)$ \\
\hline Washington & $26.1(23.8-28.3)$ & $76.2(73.8-78.6)$ & $72.8(70.2-75.4)$ & $54.7(51.9-57.5)$ & $89.4(88.1-90.8)$ \\
\hline West Virginia & $24.0(20.6-27.5)$ & $75.1(72.2-78.1)$ & $73.5(70.5-76.5)$ & $56.2(52.5-59.9)$ & 80.7 (78.8-82.6) \\
\hline Wisconsin & $22.3(18.2-26.3)$ & $76.0(72.2-79.8)$ & $70.1(65.7-74.4)$ & $52.8(47.4-58.2)$ & $85.5(83.0-88.1)$ \\
\hline Wyoming & $24.0(19.9-28.1)$ & $75.0(69.6-80.4)$ & $72.6(69.3-76.0)$ & $53.2(48.9-57.6)$ & 86.1 (83.7-88.5) \\
\hline
\end{tabular}

Abbreviations: $\mathrm{A} 1 \mathrm{C}=$ hemoglobin $\mathrm{A} 1 \mathrm{C} ; \mathrm{BP}=$ blood pressure; $\mathrm{ABCS}=$ hemoglobin $\mathrm{A} 1 \mathrm{C}$, blood pressure, cholesterol, and avoiding smoking; $\mathrm{ACS}=\mathrm{American}$ Community Survey; BRFSS = Behavioral Risk Factor Surveillance System; $\mathrm{Cl}=$ confidence interval; NHANES = National Health and Nutrition Examination Survey; non-HDL-C = nonhigh-density lipoprotein cholesterol.

* State-level estimates of A1C, BP, and non-HDL-C were created by raking and multiple imputation methods using data from 2009-2018 NHANES, 2017-2018 ACS, and 2017-2018 BRFSS; state-level estimates of nonsmoking were made directly from weight-adjusted BRFSS data, and the raking method was first used to adjust 2017-2018 BRFSS weights to the 2017-2018 ACS.

${ }^{\dagger}$ ABCS goals were defined as $\mathrm{A} 1 \mathrm{C}<8 \%, \mathrm{BP}<140 / 90 \mathrm{mmHg}$, non- $\mathrm{HDL}-\mathrm{C}<130 \mathrm{mg} / \mathrm{dL}$, and avoiding smoking.

$\S$ National average prevalence of each goal was a direct estimate from 2015-2018 NHANES.

" Some state-level estimates were below or above the $90 \% \mathrm{Cl}$ of the national prevalence. ABCS goals: Wisconsin; BP goal: Alaska, District of Columbia, Mississippi, Utah, and West Virginia; non-HDL-C goal: District of Columbia; nonsmoking goal: California, Delaware, Florida, Kentucky, Maryland, Missouri, Nebraska, New Hampshire, North Dakota, Tennessee, Utah, Washington, and West Virginia. 
highest was $62.8 \%$ in DC. The prevalence in DC was above the $90 \%$ CI of national prevalence. The lowest prevalence of achieving the nonsmoking goal (79.3\%) was in Tennessee, and the highest $(91.8 \%)$ was in Utah. When comparing the individual goals (Figure), the prevalence of achieving the nonsmoking goal was the highest, and that of achieving the non-HDL-C goal was the lowest. In addition, there was a relatively larger variation among states in achieving the nonsmoking goal than other goals.

\section{Discussion}

This is the first study to estimate the state-level prevalence of achieving ABCS goals to prevent complications of diabetes among adults with self-reported diabetes for all 50 U.S. states and DC. The study identified some states where achievements of the ABCS goals are relatively higher or lower.

Previous studies looked at the achievement of ABCS goals among persons with diabetes at the national level. One analysis using the 2007-2012 NHANES data found that among

FIGURE. Estimated prevalence* of achieving individual goals of $\mathrm{ABCS}^{\dagger}$ among adults with self-reported diabetes - United States, 2017-2018
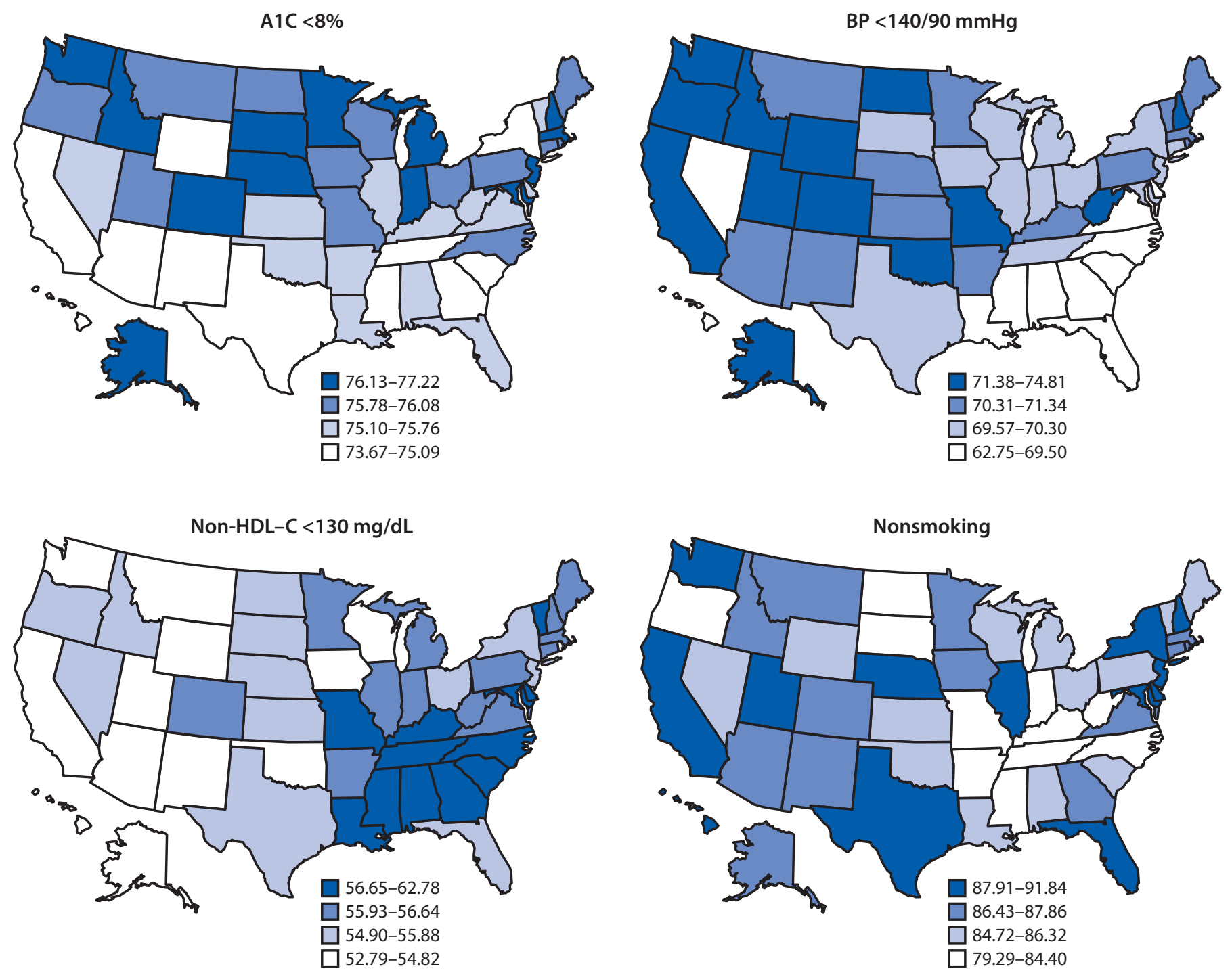

Abbreviations: $\mathrm{A} 1 \mathrm{C}=$ hemoglobin $\mathrm{A} 1 \mathrm{C} ; \mathrm{ABCS}=$ hemoglobin $\mathrm{A} 1 \mathrm{C}$, blood pressure, cholesterol, and avoiding smoking; $\mathrm{BP}=$ blood pressure; non- $\mathrm{HDL}-\mathrm{C}=$ non-highdensity lipoprotein cholesterol.

* The percentage intervals for the quantile cutoffs vary because of variations in the distribution of goal achievement.

${ }^{\dagger}$ ABCS goals were defined as A1C $<8 \%, B P<140 / 90 \mathrm{mmHg}$, non-HDL-C $<130 \mathrm{mg} / \mathrm{dL}$, and avoiding smoking (current smokers were defined as those who had $\geq 100$ cigarettes in their lifetime and were a smoker at the time of the survey). 


\section{Summary}

What is already known about this topic?

Effective management of hemoglobin A1C, blood pressure, cholesterol, and avoiding smoking (ABCS) is important in preventing complications from diabetes. Little information on state-level prevalence in achieving ABCS goals is available.

What is added by this report?

During 2017-2018, the proportion of U.S. adults with selfreported diabetes who met $A B C S$ goals was suboptimal. Only $26.4 \%$ met all the ABCS goals, $75.4 \%$ met the $\mathrm{A} 1 \mathrm{C}$ goal, $70.4 \%$ met the blood pressure goal, $55.8 \%$ met the cholesterol goal, and $86.0 \%$ were current nonsmokers.

What are the implications for public health practice?

These estimates provide data that public health departments could use in their planning efforts to achieve ABCS goals and thus reduce diabetes-related complications at the state level.

adults with diagnosed diabetes, $21.3 \%$ met all ABCS goals, and $63.7 \%$ met the goal for $\mathrm{A} 1 \mathrm{C}, 65.5 \%$ for $\mathrm{BP}<140 / 80 \mathrm{mmHg}$, $56.6 \%$ for low-density lipoprotein cholesterol $<100 \mathrm{mg} / \mathrm{dL}$, and $80.6 \%$ for nonsmoking (G). The results of the National Diabetes Statistics Report showed that during 2013-2016, $19.2 \%$ of adults aged $\geq 18$ years with diagnosed diabetes met goals for $\mathrm{A} 1 \mathrm{C}<7.0 \%$, BP $<140 / 90 \mathrm{mmHg}$, non-HDL-C $<130 \mathrm{mg} / \mathrm{dL}$, and nonsmoking; $36.4 \%$ met goals of A1C $<8.0 \%$, BP $<140 / 90 \mathrm{mmHg}$, non-HDL-C $<160 \mathrm{mg} / \mathrm{dL}$, and nonsmoking (4).

Achieving goals for ABCS can reduce the risks for diabetes complications. An analysis from the UK Prospective Diabetes Study suggested that among persons with type 2 diabetes, an intensive blood glucose control regimen reduced A1C levels by $11 \%$ over 10 years and reduced the risk for microvascular complications by $25 \%$ (3). In addition, accumulating evidence has shown that reducing BP and cholesterol levels and avoiding smoking help decrease the incidence of cardiovascular complications among persons with diabetes (5).

Some potential factors, such as access to health care and the difference in individual sociodemographic factors, might explain the variation in the achievement of ABCS goals. One study found that lack of health care coverage and low use of health care services were associated with poor management of diabetes (9). Another study suggested that persons with higher socioeconomic status were more likely to manage diabetes more effectively (10).

The findings in this report are subject to at least four limitations. First, the study sample did not include institutionalized adults, who might achieve different levels of reaching ABCS goals than do noninstitutionalized adults. Second, self-reported diabetes status and other variables might be subject to diagnosis, recall, and social desirability bias. Third, the methods applied cannot ensure that all bias was reduced; state-level estimates for A1C, BP, and non-HDL-C levels might be less precise than they would be if these variables had been measured directly, rather than relying on the multiple imputation method. Finally, possible reasons underlying state variation in the prevalence of meeting ABCS goals were not examined.

Despite increased recognition of the importance of effectively managing risk factors among adults with diabetes, the prevalence of meeting ABCS goals to reduce complications of diabetes is still suboptimal. CDC has been working closely with states to address the burden of diabetes. For example, the Diabetes State Burden Toolkit (https://nccd.cdc.gov/Toolkit/ DiabetesBurden) provides estimates of the health and economic impact of diabetes by state. In addition, CDC funds state health departments to support programs to help reduce diabetes complications (e.g., Improving the Health of Americans Through Prevention and Management of Diabetes, Heart Disease, and Stroke [DP18-1815]). ${ }^{\$ \$}$ Tracking state-level progress of ABCS levels might help identify gaps in diabetes care. There is a trade-off because direct measurement at the state level is more precise than is imputation but is more costly, whereas imputation is more practical but does not consider variation related to diabetes management programs or policies in states. Nonetheless, public health departments could use these data in their planning efforts to achieve ABCS goal levels and reduce diabetes-related complications at the state level.

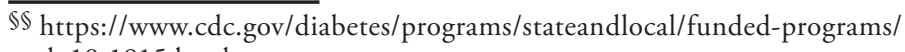
dp18-1815.html.

Corresponding author: Yu Chen, ppz4@cdc.gov.

${ }^{1}$ Division of Diabetes Translation, National Center for Chronic Disease Prevention and Health Promotion, CDC.

All authors have completed and submitted the International Committee of Medical Journal Editors form for disclosure of potential conflicts of interest. No potential conflicts of interest were disclosed.

\section{References}

1. American Diabetes Association. Economic costs of diabetes in the U.S. in 2017. Diabetes Care 2018;41:917-28. PMID:29567642 https://doi. org/10.2337/dci18-0007

2. American Diabetes Association. Standards of medical care in diabetes-2019. Diabetes Care 2019;42(Suppl 1). https://care. diabetesjournals.org/content/diacare/suppl/2018/12/17/42. Supplement_1.DC1/DC_42_S1_2019_UPDATED.pdf

3. UK Prospective Diabetes Study (UKPDS) Group. Intensive blood-glucose control with sulphonylureas or insulin compared with conventional treatment and risk of complications in patients with type 2 diabetes (UKPDS 33). Lancet 1998;352:837-53. PMID:9742976 https://doi. org/10.1016/S0140-6736(98)07019-6

4. CDC. National diabetes statistics report 2020: Atlanta, GA: US Department of Health and Human Services, CDC; 2020. https://www. cdc.gov/diabetes/library/features/diabetes-stat-report.html 
5. Lorber D. Importance of cardiovascular disease risk management in patients with type 2 diabetes mellitus. Diabetes Metab Syndr Obes 2014;7:169-83. PMID:24920930 https://doi.org/10.2147/DMSO.S61438

6. Ali MK, Bullard KM, Gregg EW, Del Rio C. A cascade of care for diabetes in the United States: visualizing the gaps. Ann Intern Med 2014;161:681-9. PMID:25402511 https://doi.org/10.7326/M14-0019

7. Marker DA, Mardon R, Jenkins F, et al. State-level estimation of diabetes and prediabetes prevalence: combining national and local survey data and clinical data. Stat Med 2018;37:3975-90. PMID:29931829 https:// doi.org/10.1002/sim.7848
8. Van Buuren S. Flexible imputation of missing data. 2nd ed. Boca Raton, FL CRC/Chapman \& Hall; 2018.

9. Zhang X, Bullard KM, Gregg EW, et al. Access to health care and control of ABCs of diabetes. Diabetes Care 2012;35:1566-71. PMID:22522664 https://doi.org/10.2337/dc12-0081

10. Piatt GA, Songer TJ, Brooks MM, et al. Impact of patient level factors on the improvement of the ABCs of diabetes. Patient Educ Couns 2011;82:266-70. PMID:20434290 https://doi.org/10.1016/j. pec.2010.04.005 